\title{
Sources of Credit Cyclicity: A Theoretical Literature Overview
}

\author{
Dmitry Vladimirovich Burakov ${ }^{1}$ \\ ${ }^{1}$ Department of Monetary Relations and Monetary Policy, Financial University under the Government of \\ Russian Federation, Moscow, Russian Federation \\ Correspondence: Dmitry V. Burakov, Department of Monetary Relations and Monetary Policy, Financial \\ University under the Government of Russian Federation, Moscow, Russian Federation. Tel: 8-967-008-2725. \\ E-mail: dbur89@yandex.ru
}

\author{
Received: Janaury 28, 2014 Accepted: February 20, 2014 Online Published: February 24, 2014 \\ doi:10.5539/res.v6n1p151 \\ URL: http://dx.doi.org/10.5539/res.v6n1p151
}

\begin{abstract}
In this article we try to identify potential sources of credit cyclicality. Unfortunately, contemporary models of the credit cycle are paying insuffiecent attention to this issue. The substitution of notions occurs quite often and reveals itself as a serious theoretical flaw. For example, in some studies the mechanism is accepted as the source of credit cyclicity. In some cases, factors of cyclical fluctuations are recognized as the main cause of such credit dynamics. Using the terminological approach, we carried out a comparative analysis of potential sources of the credit cycle, proposed in the literature on the issue. As the result of the study we offer to determine the source of the credit cycle as its basis - an element, without which changes in supply and demand for credit cannot be inherently cyclical in nature. In our opinion the sources of this phenomenon can be found in bounded rationality of lenders and borrowers, and in uncertainty of economic conditions. This approach allows us to determine the core of the credit cycle, as a mechanism of credit risk oscillations in the short-term and medium-term periods. This approach also allows us to successfully solve the theoretical controversy regarding the nature of the credit cycle, existing in the modern literature on the issue.
\end{abstract}

Keywords: credit cycle, credit risk, credit market, bounded rationality, uncertainty, banking crisis

\section{Introduction}

The problem of credit dynamics' features, its cyclical fluctuations has returned the attention of the research community and monetary authorities in many countries of the world due to the Great Recession. The need of improving the ways the credit cycle is controled, improving the methods with which the credit overheat is forecasted, solving vector non-optimality problem of loans granted by commercial and investment banks has become one of the most important tasks in achieving sustainability in the development not only of the credit market, but also in ensuring stability of economic development in general. The absence of unified theoretical statements that could describe and explain the peculiarities of cyclical dynamics of credit significantly complicates the solution of this task. Unfortunately, even nowadays measures of countercyclical regulation of credit offered by the research community, are scattered and sometimes contradictory. In some cases, combating the negative effects of the cyclical nature of credit dynamics is reduced to strengthening the requirements for the liability side of commercial and investment banks' balances (e.g., in the framework of the Basel Accords). Others believe that the solution to the problem of credit cyclicality should be linked with the problem of limited liability (Rothbard, 1962; Gollier, Koehl, \& Rochet, 1997; Sinn, 2001). In some cases, the problem of cyclicity is identified with the existing frictions in payments and bonuses schemes (Rajan, 1994). A number of authors of credit cycle's models as a root cause of the cycle highlight the role of competition and its particular qualities, as a form of coordination failures in the credit market (Ruckes, 2004; Hauswald \& Marquez, 2006). The disperion of opinions of such a scale must have certain theoretical grounds. Indeed, as shown by previous research, the problem of description and explanation of the credit cycle is directly related to different views about the role of credit organizations in the creation and/or transmission of shocks of various natures (Burakov, 2013). All models of the credit cycle, today, in one way or another, are related to the particular school. A criterion for their delimitation is quite often identified as the type of the shocking event, which leads to a shift from the upward phases to downward ones. For exogenous models (Bernanke, Gertler, \& Gilchrist, 1996; Marty, 1996; Kiyotaki \& Moore, 1997; Burakov, 2013) an external nature of the credit cycle is an intrinsic feature: a change between the upward and downward phases is the result of an exogenous shock to the credit market, while the potential of 
lenders to assess credit risk is limited. Thus, credit organizations act as recipients of credit risk from non-financial institutions. For endogenous models of the credit cycle (Kindleberger, 1975; Minsky, 1992; Berger \& Udell, 2004; Ruckes, 2004; Rötheli, 2012) changes of credit cycle's phases is aconsequence of an endogenous shock. Authors of endogenous credit cycle's models strongly believe that a shift in phases of the credit cycle is a consequence of excessive risk-taking by commercial banks, due to a number of factors, vayring from competitive pressure to bounded rationality of credit market agents.

The existence of this kind of theoretical diversity naturally affects the determination of the mechanism of credit cyclicity - those of its driving forces which lead to sustainable changes in direction of credit flows. Identification of a mechanism or a basis of the credit cycle becomes a main leitmotif of many studies, while developing measures to deal with the negative effects of credit cyclicity becomes a direct consequence of the first ones.

Unfortunately, in most cases, we can encounter a substitution of notions and the study of sources of credit cyclicity is quite often reduced to identifying the factors amplifying credit oscillations or restraining them. The lack of clear terminology is thus a circumstance that complicates the achievement of significant results in the field of the study and postpones an achievement of stability in credit dynamics. Also of considerable influence on the determination of sources of credit cycle are the views upon its nature. Taking into account these differences in views, it should be noted that this kind of dissonance also does not contribute to the theoretical unity, nor in the question about the sources of the credit cycle or in the development of measures to contain it in the acceptable for the society borders.

In this study we try to find a solution to this problem. Given the existing gaps in the terminology of the credit cycle, we are aiming to identify the sources of the credit cycle, its foundation - that driving force, without which the credit dynamics, as changes in aggregate credit transactions between lenders and borrowers, could not be cyclical in nature. We believe that the basis, the source of the credit cycle is on the one hand can be found in bounded rationality of economic actors. Biases in the perception of credit risk lead to deviations in the process of assessment, which, in turn, affect the generated expectations of credit agents, as well as increase (reduce) the willingness to accept risk, due to its underestimation (overestimation) on the upward (downward) phases. On the other hand, given the existence of tail risks and uncertainty of economic conditions, we believe that the occurrence of unforeseen events is also an essential element of the credit cycle's basis It is important to note that in our understanding, the credit cycle is not a sustainable or constantly recurring event, as in the views of the first theorist of the credit cycle, J. Mills (Mills, 1867), rather we tend to follow the views of W. Bagehot (Bagehot, 1873), considering a credit cycle as a heterogeneous process related to shocking events of different nature.

At the same time, we propose to separate the notion of "sources of the credit cycle" from the notion of "factor of the credit cycle". In our understanding, sources of credit cyclicity provide the basis for the oscillatory dynamics of credit. Factors of the cycle, or amplification channels, affect the amplitude and determine the nature of the credit cycle, but are not its basis. From our point of view, credit cyclicity is quite closely connected with the cycles in credit risk, as a process of cumulative accumulation on the upward phases and subsequent transformation in losses on the downward phases of the cycle under the impact of a shock or shocks of a specific nature. In case of endogenous nature of the shock, the nature of the cycle is endogenous; in case of exogenous (social disturbances, disasters, wars) - exogenous. Thus, the proof of the fidelity of this hypothesis will not only enrich the existing theoretical approaches to studying credit cycles and finding tools to manage it properly, but also will help to remove the theoretical contradiction between existing schools of credit cyclicity.

The structure of this paper is organized as follows and includes the following sections: section 2 presents a brief summary of the terminological approach used for the analysis of potential sources of credit cycle; section 3 gives an overview of existing credit cycle models for determining the sources of the cycle; through the carried out comparative analysis, based on the method of proof by contradiction, a number of potential sources is pointed out; section 4 summarizes the results of the conducted study; section 5 presents a bibliographical list of papers used in the preparation and conduct of this study.

\section{Methodologies}

Since the problem of credit cyclicity riveted attention of the research community again only in the end of XX century, the methods used for research have evolved quickly. Unfortunately, most of the attention of researchers in studying the problem of the credit cycle is still focused on the peculiarities of determining the phases of the credit cycle, points of transition from one phase to another. A lot of attention is given to methods of forecasting credit bubbles' occurance. But for the most part, quantitative research of the credit cycle is built on the classical methodology of determining phases of the business cycle and their changes, developed by American researchers (Burns \& Mitchell, 1946). However, alternative approaches also exist (Rötheli, 2012; Burakov, 2013). The 
problem of determining the sources of the credit cycle, their basis, of ways to study this issue in modern literature is presented quite poorly and its roots date back mainly to the empirical works of scientists of the XIX century (Mills, 1867; Bagehot, 1873; Hall, 1927). Thus, clear and unified approaches to identification of sources of the credit cycle today do not exist.

Moreover, contemporary approaches to the definition of the credit cycle are also deprived of unity. In some cases, the credit cycle is defined as changes in the willingness of banks to lend funds to borrowers. In other cases credit cycle is understood as a change in lending standards, in third - systematic changes in the level of leverage, etc. We tend to use the following definition of the credit cycle, which seems to be more complex and holistic - a variety of dynamics of value lent by creditors to borrowers, which is characterized by steady changes of upward phases by downward ones, defined by subject-contextual specificity of the reproduction process (Burakov, 2013). This approach to the definition allows not only to remove the theoretical contradictions between various schools of credit cyclicity but also to achieve integrity in the definition of the essence of this phenomenon, including phases' specifics, and the heterogeneity of credit cycle's nature.

Considering the existing terminological pluralism and methodological ambiguity, we set ourselves a task to define a number of methods, which may contribute in general to identify potential sources of the credit cycle. Starting from the distinction between the notions of "source" and "factor", we conduct a theoretical analysis of existing models of the credit cycle to identify the basis in their concepts. Given the terminological uncertainty of many studies, we attempt to assess the possibility of a potential factor to be the source of credit cyclicity on the basis of several criteria.

Under the source we understand the driving force of the credit cycle, its basis - a set of conditions, which help the cyclic pattern of credit movement to exist. Under the factor of the credit cycle we understand a condition, which have an influence on the amplitude of the cycle's oscillation. The main criterion to distinguish these concepts we believe to be their exclusivity. In other words, an analysed element has to be included in the sources if and only if in its absence cyclical pattern of credit dynamics is not observed. Roughly speaking, we use the classic mathematical method of the proof of the thesis by contradiction.

Framework for the conduct of the study is the combination of theoretical and empirical studies of different authors on the issue of the credit cycle. As an evidence of a factor being able to play a role of a source of the cycle studies showing validity or falsity of the thesis are used.

In order to ensure the clarity and reliability of the method used in this study we present an example:

Thesis. It is believed that the root cause of the credit cycle's existence is the establishment of the fractional reserve banking system.

Reasoning: increasing transactions between the Bank of England and the Bank of Amsterdam in the XVIII century in the conditions of increased demand for credit resources has led to the need of reducing reserve requirements of species needed to meet the demand for exchanging bank bills. Such an outstanding increase in the supply of credit has led to the formation of credit inflation, overheating of asset markets, creation of credit bubbles and formation of prerequisits of further crisis.

Counter-thesis. If the formation of fractional reserve banking system is the source of the credit cycle, then without first last can not exist.

Reasoning: the existing research shows that regular periods of booms and busts appeared long before the advent of fractional reserve banking system. For example, the financial crises of the second half of the XVI century occurred before the creation of this system. Then, it makes sense to assume that a system of fractional reserve bankin system is nothing more but a factor affecting the amplitude of the credit cycle and its duration, rather than it is the basis of its appearance and existence.

\section{Theoretical Overview of Credit Cycle's Potential Sources}

\subsection{Central Assumptions of Credit Cycle's Models}

Basing on the research of a substantial array of literature on the issue of the credit cycle, we came to the conclusion that, overall, the researchers agree on the mechanism of credit cycles, however, they are in opposition to each other about the nature of the cycle. This issue may be stated in the following three theses. The central thesis is visible in each of analyzed papers, beginning from the XVIII century. It's stated that the core of the credit cycle, as the specific dynamics of credit movement, is the dynamics of credit risk. It is the accumulation process on the upward phases and further implementation in the form of non-perfroming loans and loan losses, which is the trigger initiating the change of phases - transition from the upward movement to downward. An 
issue of quantitative proportions of credit risk in this case departs on the second plan and is mostly responsible for the amplitude of the cycle and its duration, while the very existence of cyclic pattern in credit risk dynamics is the basis of the credit cycle (see, for example, Burakov, 2013). Unfortunately, at this stage, the certainty and unity of views of various researchers come to an end.

The second thesis reveals the approaches to the concept of credit risk and its role in ensuring existence of the credit cycle. In this case, an idea about the mechanism of the cycle is in certain relationship with the view on its nature. It is the credit risk serving the main criterion that defines the differences in the views of researchers upon other distinct features of the cycle. Given the above thesis about existence of two schools of credit cyclicity, it is worth noting that differences in views about the nature of the cycle are the result of differences in authors' perception of the potential of credit institutions in evaluating credit risk. Thus, according to the exogenous models of the credit cycle, lenders are the recipients and distributors of credit risk, due to their limited capacity of assessing the last on the one hand and the time limitations on the other. The limited capacity of risk assessment is the result of significant information asymmetries in the credit market, bringing to life the problems of adverse selection and moral hazard. The solution of these problems through the operation of interest rate's clearing function is difficult due to incomplete information. Time limitations in conditions of a rigid competition and, consequently, high elasticity of demand and supply of credit, lead to the necessity of searching tools for insuring credit risks and/or their transfer to other market participants (for example, through the securitization mechanism). Proponents of this school almost put the sign of equality between risk and uncertainty. It is assumed, that risk assessment by credit agents is possible, but restrained due to existing condition of asymmetric information.

On the other hand, the authors of endogenous models of the credit cycle begin their research from completely opposite assumptions. In their perception, the lenders are not recipients of credit risk; rather they play a role of their creators. In this case a problem of limited capacity of risk assessment due to the context of the market plays a secondary role. The vital part of these models is its rationale. Starting from the assumption of bounded rationality, in these models, the main place is given to underestimation (overestimation) and/or consious taking of excess credit risk as a result of cognitive and affective biases, heuristics in decision-making process, as well as various market forces, such as competition, monetary policy, etc. In other words, in the endogenous models of the credit cycle lenders themselves create and take on excessive credit risk either under the influence of bounded rationality or due to a shift in bargaining power in the credit market.

However, the goal of identifying sources of credit cyclicty still remains in the background, and the main emphasis of researches is reduced to the description and/or explanation, in the case of endogenous (exogenous) models, periods of growth (decline) in the credit market.

\subsection{Comparative Analysis of Potential Sources of the Credit Cycle}

\subsubsection{Competitive Forces in Explaining the Credit Cycle}

Thesis. In a number of studies a point of view is offered that competition is the driving force (the source) of the credit cycle. (Gorton \& He, 2008)

Reasoning: given the high elasticity of credit markets in developed countries, the need to maintain the rate of return of commercial bank's shares above the market average is pushing lenders to a cyclical reduction in lending standards through various manifestations. The credit cycle then appears as follows: the need to achieve the desired results given the limited quality of demand for credit, is forcing banks to reduce requirements to borrowers. Thus, the process of accumulation of credit risk fosters. Due to the occurance of shocking event, the acumulated risks are transformed into non-perfroming loans and losses. In some cases, competition comes in the form of herd behavior ffect, when creditors, making a decision on the loan application, are guided by the actions of other players in the credit market. (Acharya \& Yorulmazer, 2008). In other cases, the competition is manifested in the effect of the winner's curse: information asymmetry, coupled with the high elasticity of demand for credit pushes to meeting demand of possibly low quality borrowers, which increases the received credit risk. The downward phase of the credit cycle is also associated with the occurence of shocking event. (Thaler, 1988) (Note 1)

Counter-thesis. If competition is the source of the credit cycle, then in the absence of the former cyclical movement of credit should not exist.

Reasoning: studies of the credit markets, which established the absence of competition between players, either due to the dominance of state banks or due to institutional trap effects in the credit market, (Burakov, 2014), or, in view of the central-planned economies (Glasner, 1997), or due to a substantial tightening of control over the 
credit market (Haldane, 2010) show that even in the absence or substantial reduction of competition between players, cyclical movement of credit does still esixt. Then it can be assumed that competition, being the form of the relationship between market players is a factor of the credit cycle, and provides a significant impact on the amplitude and frequency of oscillations of credit dynamics.

\subsubsection{Limited Liability Problem and the Credit Cycle}

Thesis. In a number of studies a view that the limited liability of commercial banks is the driving force of the cyclical movement of credit is offered (Rothbard, 1962; Gollier et al., 1997; Sinn, 2001).

Reasoning: the problem of limited liability of commercial banks implies the presence of a certain kind of moral hazard, which reinforces the willingness of credit organizations to take heightened levels of credit risk. Manifestations of limited liability to date include, for example, limited liability of banks before depositors, or management before shareholders. The mechanism of limited liability's influence on the credit cycle reveals itself in a following way: given the imbalance between fixed potential losses of the commercial bank and uncertain possible income, a tendency to increase the risks taken on the upward phases of the cycle arises. On the other hand, the presence of deposit insurance system ceteris paribus pushes depositors to search for higher rates, which, in turn, forces the banks to seek higher returns for saving the interest margin. The second type of this problem is a consequence of the first and includes a decline in bank managers' efforts due to fixed potential losses (in this case, limited liability appears as a consequence of non-optimal contracts). In other words, the credit cycle in the prism of limited liability problem is presented as a change in multiple equilibria between borrowers with high quality projects and high-risk borrowers, in favor of the latter, which leads to the formation of instability in the credit market, constantly manifested in burst of credit bubbles. Mechanism of the cycle is determined by the shift of credit supply towards more profitable and more risky pool of borrowers.

Counter-thesis. If limited liability problem in commercial banks is the source of the credit cycle, then in the absence of the former cyclic movement of credit should not exist.

Reasoning: historical studies of the role of the limited liability in cyclical movement of credit show that even a substantial increase in responsibility of commercial banks before depositors (in the conditions of absence of deposit insurance schemes) by increasing capital requirements does not protect banks from possible banking panics (Glasner, 1997; Grossman \& Imai, 2011), on the other hand, toughening of responsibility (in the form of increasing the potential losses of the creditor) does not reduce the appetite toward excessive credit risk taking in case of a substantial increase in market rate of return (Burakov, 2014).

\subsubsection{Frictions on Bank Labour Market and the Credit Cycle}

Thesis. In a number of studies a view that the labor motivation system for employees of commercial banks and features of labour reproduction process are driving the cyclicality of credit is offered (Rajan, 1994; Berger \& Udell, 2004).

Reasoning: credit institutions are inherent with systemic changes in lending standards associated with concern of bank's management with their reputation. This in turn forces them to focus on short-term results. For example, top management of a credit organization is more likely to get a promotion or to be employed by another bank, assuming the current financial results are positive. This block of the models holds an assumption according to which some lenders have a greater potential in terms of determining the profitable credit applications. This difference is crucial in the conditions of economic growth. When the economic conditions are favorable only to loans granted by lenders with the high level of the potential to evaluate credit demand, low probability of default is inherent. In condition of a recession, the difference in quality between different lenders does not play any role. Reputational concerns then create a systematic and sustainable deviation towards excessive easing of lending standards by a number of banks on the upward phases and their tightening in the period of recession.

Another variation of the importance of labour market in the development of the credit cycle is connected with the fact that the problems of institutional memory can bring to life a steady pattern in the behaviour of creditors, which is associated with the deterioration of the abilities of a credit institution in terms of determining the potentially default credit applications and an easing of credit standards throughout the credit cycle of the organization.

Counter-thesis. If frictions in the labour market for banking organizations are the sources of the credit cycle, then in the absence of them, cyclical movement of credit should not exist.

Reasoning: it's worth noting, that even in the absence of a rigid binding of labour remuneration to the implementation of sales plans in order to ensure short-term results of a commercial bank, cyclical movement of credit continues to exist. For example, policies to promote short-term results had not been widely implemented 
in the second half of the XIX century in the United States. The first marketing strategies and development of the concept of «sales» appeared in banking industry only in the early XX century, at the same time the credit cycle has already existed then. (Haldane, 2010; Rotheli, 2012; Burakov, 2014;).

The change of generations in ensuring continuity of operations of the banking organization is more of a long-term effect, while the average duration of the credit cycle is, according to various estimates, lies in the range of 5 to 12,8 to 15 years. (Haldane, 2010).

\subsubsection{The Role of the Business Cycle in Credit Oscillations}

Thesis. In a number of studies a view that sources of the credit cycle are the fluctuations in business activity, otherwise the business cycle is offered. (Bernanke et al., 1996; Marti, 1996; Kiyotaki \& Moore, 1997; Geanokoplos, 2011)

Reasoning: it is believed that credit cyclicality is a consequence of the vibrational motion of the economy, and shocks of the economic nature which penetrate into the banking sector through a number of channels. These include balance sheet channel, collateral channel and expectations channel. In this case the mechanism of the credit cycle is represented as a reflection of changes in the economic environment. In the conditions of upward economic dynamics, the balance sheet value of the borrower's company rises, as rises the market price of the collateral, and this leads to increased lending opportunities. In case of exogenous shocking event's occurance, balance sheet value, value of collateral and expectations of creditors shrink and deteriorate, causing the credit crunch and beginning of the downward trend in the credit market. In these models the core of the credit cycle continues to be a credit risk, but the credit market is given nothing but a subservient role. Determining influence is given overall to the business cycle.

Counter-thesis. If a business cycle is the source of the credit cycle, then the phases of credit and business cycles should be synchronous, and duration of these cycles must coincide. In other words, in absence of a business cycle as a set of its phases, phases of the credit cycle can not exist.

Reasoning: numerous studies of the relationship between credit and business cycles show that 1) the credit cycle compared with the business cycle is inherently reactive in nature (as a rule, the credit cycle lags for the period from 1 quarter up to 1 year after the business cycle) (Haldane, 2010);2) there is an asynchrony in peaks and troughs between a credit cycle and a business cycle. In some cases, the phase of credit crunch exists in parallel with the expansion phase of the business cycle that does not meet the requirement of synchronicity (for example, in the USA, Poland, Russia). Thus, on the one hand we can assume that the credit cycle is not a mirror reflection of the business environment. On the other hand, the identification of the source of a credit cycle as a business cycle is a methodological inaccuracy, a kind of incompleteness of the analysis process, a thing in itself. A source of a credit cycle acts as a set of conditions that bring him to life. Considering one cycle as the source of another cycle seems to be illegitimate.

\subsubsection{Bounded Rationality and the Credit Cycle}

Thesis. In a number of studies a view that the source of the credit cycle is bounded rationality of actors is offered (Kindleberger, 1975; Minsky, 1992; Haldane, 2010; Rötheli, 2012; Burakov, 2014)

Reasoning: it is believed that the credit cyclicality is a consequence of bounded rationality of participants of credit relations. Under bounded rationality it's usually meant that the behavior of the participants of relations is contrary to the central assumptions of the neoclassical school of economics: the denial of maximizing behavior, but introducing a desire to achieve a certain aspiration level depending on a reference point (Kahneman \& Tversky, 1975), processing information based on the use of heuristics and under the influence of cognitive, affective biases, as well as assuming inconsistency of intertemporal preferences, as well as the attitude towards risk. According to the behavioral models of the credit cycle, built on the achievements of behavioral economics, cyclical movement of credit is a consequence of the interaction of a large number of mental forces (optimistic bias, overconfidence effect, short-term horizons, gender effects, different heuristics etc.), leading to deviations in the process of perception, evaluation and formation of the attitude toward risk. Accordingly, the underestimation of credit risk leads to its unconscious adoption of a systematic character. As the credit risk is accumulating, the onset of the crisis event is approaching. The trigger in the form of a shock starts the process of transition from the upward phases to downward ones, amplifying risk and loss aversion. It is important to note that in these models both underestimation of risk by lenders and borrowers and conscious excessive risk taking, for example, under the influence of framing, could be explained (see, for example, Haldane, 2010, Burakov, 2014). In most cases, these models belong to the Endogenuity School and seek to explain the formation of credit bubbles.

Counter-thesis. If bounded rationality is the source of the credit cycle, then it must meet requirements for 
completeness - to have the ability to describe and explain all periods of credit boom and bust.

Reasoning: the existing studies of the credit cycle show that in some cases, periods of credit overheating, estimated by available to the research community methods, do not precede the phases of credit crunch (e.g. in case of a technical recession of 1990-1991 in the United States, the banking panic of 2004 in Russia, the crisis of 1993-1994 in Italy, the credit crunch of 2004-2005 in Poland). These periods were not characterized either by excessive expansion of credit or loose monetary policy. In this case, a certain role was played by the factor of unpredictability. In case of the US, generally accepted explanation for this Recession is a sharp rise in oil prices, in case of Russia - the Central Bank's actions aimed at combating criminal issues in banking sector at that time, in case of Italy - unexpected consequences of the Pension Reform, in case of Poland - joining the European Union.

Thus, bounded rationality can serve as a source of credit cycles, but it's not the only condition generating them. In our opinion it exists in parallel with the condition of uncertainty of economic environment.

\section{Conclusion}

In the result of a carried out research we came to conclusion that the problem of determining the sources of the credit cycle still retains its relevance. Fragmentation and the presence of lacunae in the approaches used to identify the driving forces of credit cyclicity leaves its mark on the developed theoretical models for describing and explaining the credit dynamics. In our opinion, the definition of the source of the credit cycle is a key goal for achieving success in its management. Based on the analysis of different views on potential sources, we assume that among others bounded rationality of market participants, as well as the uncertainty of economic conditions should be pointed out. These phenomena are key conditions, without which it is impossible to comprehensively explain the cyclical motion of credit risk as the basis of the credit cycle. The basis, in turn, determines the pattern of upward and downward phases in credit dynamics. To improve the quality of managing the dynamics of credit risk it is necessary to make a distinction between the conditions inherent in credit, and not only, relations and conditions, disposable - factors affecting the magnitude and duration of the credit cycle. Further research of the credit cycle issue, in our opinion, can be connected with formalization of factors of credit cyclicity as amplification channels of credit risk, as well as with searching the tools to describe and counter them.

\section{References}

Acharya, V. V. (2009). A theory of systemic risk and design of prudential bank regulation. Journal of Financial Stability, 5(3), 224-255. http://dx.doi.org/10.1016/j.jfs.2009.02.001

Acharya, V. V., \& Yorulmazer, T. (2008). Information contagion and bank herding. Journal of Money, Credit and Banking, 40(1), 215-231. http://dx.doi.org/10.1111/j.1538-4616.2008.00110.x

Bagehot, W. (1873). Lombard street: a description of the money market. London: Henry S. King and Co. http://dx.doi.org/10.1017/CBO9781139093620

Barber, B. M., \& Odean, T., (2001). Boys will be boys: Gender, overconfidence, and common stock investment. Quarterly Journal of Economics, 116, 261-292. http://dx.doi.org/10.1162/003355301556400

Beck T., Behr P., \& Güttler A. (2010). Gender and banking; are women better loan officers? European Banking Center, Discussion Paper No. 2009-19. http://dx.doi.org/10.1093/rof/rfs028

Berger, A., \& Udell, G. (2004). The institutional memory hypothesis and the procyclicality of bank lending behavior. Journal of Financial Intermediation, 13(4), 458-495. http://dx.doi.org/10.1016/j.jfi.2004.06.006

Bernanke, B., Gertler, M., \& Gilchrist, S. (1996). The financial accelerator and the flight to quality. The Review of Economics and Statistics, 78(1), 1-15. http://dx.doi.org/10.2307/2109844

Birkchandan, S., Hirshleifer, D., \& Welch, I. (1998). Learning from the behavior of others: Conformity, fads, and informational cascades. Journal of Economic Perspectives, 12, 151-170. http://dx.doi.org/10.1257/jep.12.3.151

Burakov, D.V. (2013). Exogenous credit cycle: An experimental study. World Applied Sciences Journal, 26(6), 733-736. http://dx.doi.org/10.5829/idosi.wasj.2013.26.06.13510

Burakov, D. V. (2014). Does framing affect risk attitude? Experimental evidence from credit market. American Journal of Applied Sciences, 11, 391-395. http://dx.doi.org/10.3844/ajassp.2014.391.395

Burns, A. F., \& Mitchell, W. C. (1946). Measuring business cycles. New York, National Bureau of Economic Research. 
Croson, R., \& Gneezy, U. (2009). Gender differences in preferences, journal of economic literature. Journal of Economic Literature, 47(2), 448-474. http://dx.doi.org/10.1257/jel.47.2.448

Demirguc-Kunt, A., \& Detragiache, E. (1998). The determinants of banking crises in developing and developed countries. IMF Staff Papers, 45(1). http://dx.doi.org/10.1596/1813-9450-1828

Geanakoplos, J. (2010). The leverage cycle. NBER Macroeconomics Annual 2009 (Vol. 24, pp. 1-65). University of Chicago Press. http://dx.doi.org/10.2139/ssrn.1539483

Glasner, D. (1997). Business cycles and depressions: An encyclopedia. Garland Publishing Inc., New York \& London.

Gollier, Ch., Koehl, P.- F., \& Rochet, J.- C. (1997). Risk-Taking Behavior with Limited Liability and Risk Aversion. The Journal of Risk and Insurance, 64(2), 347-370. http://dx.doi.org/10.2307/253734

Gonzales-Hermosillo, B. (1999). Determinants of ex-ante banking system distress: a macro-micro empirical exploration of some recent episodes. IMF Working Papers (p. 33). Washington DC.

Gorton, G., \& He, P. (2008). Bank Credit Cycles. Review of Economic Studies, 75(4), 1181-1214. http://dx.doi.org/10.1111/j.1467-937X.2008.00497.x

Grossman, R. S., \& Imai M. (2011). Contingent Capital and Bank Risk-Taking among British Banks before World War I. The Economic History Review, 66(1), 132-155. http://dx.doi.org/ 10.1111/j.1468-0289.2011.00638.x

Guttentag J., Herring M., \& Richard, J. (1986). Disaster myopia in international banking. Princeton University Essays in International Finance, 164.

Haldane, A. (2010). Curbing the credit cycle. Speech presented at the Columbia University Center on Capitalism and Society Annual Conference, New York.

Hall, L. W. (1927). Banking cycles. University Press.

Hauswald, R., \& Marquez, R. (2006). Competition and strategic information acquisition in credit markets. Review of Economic Studies, 19, 967-1000. http://dx.doi.org/10.1093/rfs/hhj021

Holmstrom, B., \& Tirole, J. (1997). Financial intermediation, loanable funds, and the real sector. Quarterly Journal of Economics, 112, 663- 92. http://dx.doi.org/10.1162/003355397555316

Kahneman, D., \& Tversky, A. (1979). Prospect Theory: An Analysis of Decision under Risk. Econometrica, 47(2), 263-292. http://dx.doi.org/10.2307/1914185

Kindleberger, Ch. (1975). Manias, panics, and crashes: A history of financial crises. Palgrave Macmillan.

Kiyotaki, N., \& Moore, J., (1997). Credit cycles. Journal of Political Economy, 105(2), 211-248. http://dx.doi.org/10.1086/262072

Marti, M. S. (1996). Boundedly rational credit cycles. Economics Working Paper 156.

Mills, J. (1867). On credit cycles and the origin of commercial panics. Financial crises and periods of industrial and commercial depression. Burton, T. E. (1931[1902]).

Minsky, H., (1992). The financial instability hypothesis. Working Paper No. 74, The Jerome Levy Economics Institute of Bard College. http://dx.doi.org/10.2139/ssrn.161024

Quagliariello, M. (2006). Bank's riskiness over the business cycle: A panel analysis on Italian intermediaries. Banca D'Italia. Temi di discussione del Servizio Studi.

Rajan, R. (1994). Why bank credit policies fluctuate: A theory and some evidence. Quarterly Journal of Economics, 109(2), 399-441. http://dx.doi.org/10.2307/2118468

Rothbard, M. (1962, 2004). Man, economy and state (with Power and market). Auburn, Ala.: Ludwig von Mises Institute.

Rötheli, T. F. (2012). Boundedly rational banks' contribution to the credit cycle. Journal of Socio-Economics, 41(5), 730-737. http://dx.doi.org/10.1155/2012/961316

Ruckes, M. (2004). Bank competition and credit standards. Review of Financial Studies, 17(Winter 2004), 1073-1102. http://dx.doi.org/10.1093/rfs/hhh011

Brander, J. A., \& Spencer, B. J. (1989). Moral Hazard and Limited Liability: Implications for the Theory of the Firm. International Economic Review, 30(4), 833-849. http://dx.doi.org/10.2307/2526754 
Sinn, H.- W. (2001). Risk taking, limited liability and the competition of bank regulators. NBER Working Paper No. 8669. NBER. http://dx.doi.org/10.1002/9780470774175.ch7

Thaler, R. H. (1988). Anomalies: The Winner's Curse. Journal of Economic Perspectives, 2(1), 191-202. http://dx.doi.org/10.1257/jep.2.1.191

\section{Note}

Note 1. Impact of competition on changes of willingness to take credit risk in modern literature on the issue is mainly represented as coordination failures caused by the actions of other players and their incorrect perception and assessment of credit risk.

\section{Copyrights}

Copyright for this article is retained by the author(s), with first publication rights granted to the journal.

This is an open-access article distributed under the terms and conditions of the Creative Commons Attribution license (http://creativecommons.org/licenses/by/3.0/). 